\title{
OFICINAS PEDAGÓGICAS NO EXERCÍCIO DA CRIATIVIDADE E EDUCAÇÃO PERMANENTE NA VELHICE ${ }^{1}$
}

\author{
Monize Ferreira Amorim Barros* \\ Silvana Búrigo ${ }^{* *}$
}

\section{Resumo}

Este artigo tem por objetivo mostrar a relação entre Oficinas Pedagógicas como Espaço Educativo para Despertar a Criatividade e Incentivo à Educação Permanente de Idosos. Ele é resultado de uma intervenção prática realizada por uma Assistente Social e uma Fisioterapeuta com dezessete (17) alunos idosos do Núcleo de Estudos da Terceira Idade $\left(\mathrm{NETI}^{2}\right)$ da Universidade Federal de Santa Catarina (UFSC), por meio da realização da Oficina Pedagógica “Despertar para o Criar.” A prática pedagógica serviu ainda, de mediação ao exercício científico de produção de conhecimento materializado em uma monografia e possibilitou o título de Especialista em Gerontologia às autoras. A monografia "O Espaço das Oficinas Pedagógicas no Exercício da Criatividade e Educação Permanente na Velhice”, discorre referenciais teóricos sobre criatividade, educação permanente e oficinas pedagógicas e apresenta as questões de pesquisa que foram comprovadas por meio da investigação, de abordagem qualitativa. Tais questões confirmam a importância da criatividade na vida dos idosos; que ela gera prazer e alegria, que enriquece a vida, que pode ser despertada com a abertura de espaços pedagógicos onde o ambiente encorajador e positivo favoreça a expressão do potencial criador e que o despertar do potencial criativo dos idosos também pode trazer um envelhecimento com a perspectiva de educação permanente. Finalmente, apresenta a gerontologia como um campo repleto de possibilidades criativas exigindo profissionais abertos especialmente à criatividade.

\footnotetext{
* Fisioterapeuta especialista em Gerontologia pela UFSC. Facilitadora da Oficina "Despertar para o Criar “-NETI/USFC. E-mail: mfabarros@hotmail.com

** Assistente Social especialista em Gerontologia pela UFSC.E-mail: silvanaburigo@hotmail.com

${ }^{1}$ Monografia apresentada ao Curso de Especialização em Gerontologia do Núcleo de Estudos da Terceira Idade (NETI), na Universidade Federal de Santa Catarina (UFSC) como requisito parcial para a obtenção do grau de Especialista, orientado pela Prof ${ }^{a}$. Maria Celina da Silva Crema - Mestre em Educação/Ensino. Prof ${ }^{a}$ de Carreira da UFSC.

2 NETI: objetiva colocar o conhecimento da Gerontologia à disposição da comunidade, desenvolvendo estudos e pesquisas, inserindo e promovendo as pessoas da terceira idade no meio acadêmico, como sujeito em transformação e transformador da sociedade.
} 
Palavras-chave: Criatividade. Idoso. Educação Permanente. Oficina Pedagógica.

\section{Introdução}

Ao envelhecer é importante a retomada do potencial criativo que em muitos idosos pode estar esquecido ou adormecido. Para Neri (2000), o envelhecimento é experimentado de maneira singular, ou percebido de maneira diferente pelas pessoas e depende também da interação de múltiplos fatores bio-psico-sociais e dos próprios conceitos de tempo, idade e envelhecimento. Com o fenômeno da criatividade acontece algo semelhante e as pessoas que costumam exercitar sua criatividade podem desenvolver seu potencial criativo de maneira mais eficiente e flexível.

Pretendemos neste estudo mostrar a relação entre idosos, exercício da criatividade e espaços educativos para o criar. Elegemos as Oficinas Pedagógicas como meio/instrumento para estimular a criatividade dos idosos, levando em consideração a importância de uma educação ao longo da vida que enfatize o continuar aprendendo, convivendo, ensinando e buscando sempre a descoberta e o reconhecimento das potencialidades e limites do indivíduo.

O assunto aqui exposto é fruto do trabalho elaborado para a obtenção do título de especialista em Gerontologia da Universidade Federal de Santa Catarina - UFSC/NETI, que teve o duplo desafio: realizar uma intervenção prática (Oficina Pedagógica de Criatividade) e através dela, desenvolver uma pesquisa científica que revelasse as relações sobre criatividade, idosos e oficinas pedagógicas. Foi desenvolvido junto ao NETI (Núcleo de Estudos da Terceira Idade) da Universidade Federal de Santa Catarina que é o Órgão de coordenação, execução e avaliação de programas voltados para a Gerontologia.

A Oficina Pedagógica de Criatividade intitulada "Despertar para o Criar" aconteceu em novembro de 2003 com duração de doze (12) horas em dois (2) dias consecutivos. Participaram da Oficina dezessete (17) alunos na faixa etária de média de 65 anos, oriundos do NETI, sendo quinze (15) do sexo feminino e dois (2) do sexo masculino. Quanto à escolaridade dos participantes, apenas uma pessoa possuía a Educação Fundamental; dez delas

o Ensino Médio, e seis, formação superior. A Oficina teve um enfoque teórico 
e prático. Abordou os temas criatividade, envelhecimento bem-sucedido e educação permanente por meio da utilização de vários instrumentos e técnicas como: apresentação teórico-expositiva, dinâmicas de grupo, debates, reflexões individuais e grupais, vivências lúdicas de relaxamento e sensibilização.

Na investigação para analisar a importância das Oficinas Educativas para o criar, nos valemos do método qualitativo e análise de conteúdo à luz da teoria, onde se buscou apreender o fenômeno da criatividade quando de seu processo durante a oficina. $O$ interesse esteve voltado para o estímulo ao exercício da criação. Houve uma busca do significado que o idoso dava ao seu potencial e exercício criador. Os resultados da pesquisa foram descritos e analisados interpretativamente. Segundo Minayo (1996, p. 21-22) a abordagem qualitativa " [ . . . ] se preocupa, nas Ciências Sociais, com um nível de realidade que não pode ser quantificada. Ou seja, ela trabalha com o universo de significados, motivos, aspirações, crenças, valores e atitudes, o que corresponde a um espaço mais profundo nas relações, dos processos e dos fenômenos, que não podem ser reduzidos à operacionalização das variáveis."

Como instrumentos e técnicas de investigação, adotou-se a observação direta participante e não participante, conduzindo a oficina e fazendo anotações no caderno de campo, e também a observação indireta por meio da aplicação de questionário com perguntas abertas. A análise interpretativa do material colhido na Oficina e na aplicação de questionário apoiou-se segundo Triviños (1987, p. 173) " [ . . ] ] nos resultados alcançados no estudo (resposta aos instrumentos); na fundamentação teórica (manejo dos conceitos-chaves das teorias e de outros pontos de vista); na experiência pessoal do investigador."

As pesquisadoras assumiram simultaneamente o papel de atoras e pesquisadoras do processo. Enquanto atoras, atuaram como professores (mediadoras, dinamizadoras, apoiadoras, facilitadoras, animadoras) juntos aos idosos, sensibilizando-os, estimulando-os para a adesão e ação frente à atitude criadora. Como autoras assumiram a tarefa de produzir conhecimento relativo à criatividade dos idosos e o espaço educativo das oficinas pedagógicas enquanto processo interrelacional.

A importância do processo de aprendizagem teório-prático e da descoberta da criatividade na velhice através de um espaço chamado Oficinas Educativas para a Criatividade em Idosos, entende-se, é condição necessária para que se possa sair do discurso intelectual sobre qualidade de vida na velhice e partir para a prática dos acontecimentos. 


\section{0 que é Criatividade?}

O ser humano cria no intuito de entender seus instintos, seus impulsos (conscientes e inconscientes), e busca desenvolver suas habilidades criativas para revelar suas potencialidades (o que é possível ser feito), seus limites (o que ainda não sabe fazer), bem como a sua própria natureza (PFEIFER, 2001).

Esta definição apresenta o ser humano como o centro da criatividade e por isto é relevante para entender a natureza deste trabalho que buscou em cada atividade, o re-conhecimento do idoso quanto aos vários aspectos de si mesmo em relação a sua criatividade. Aspectos que podem ser limitantes, potencializantes e também passíveis de oferecer uma melhor aceitação e compreensão de si mesmos.

Wechsler, ${ }^{3}$ apud Godoy, quando aborda a velhice, aponta para a importância da curiosidade do indivíduo idoso, concebendo-a não como um momento para esperar a morte, mas sim um momento de estimular a pessoa a realizar a sua missão criativa e de sentir que foi relevante para a humanidade.

Também para McMurray, ${ }^{4}$ apud Godoy, a experiência do processo criativo, seja na forma de arte, ou qualquer experiência, enriquece a vida da pessoa idosa. $\mathrm{O}$ ato de se deixar experienciar facilita a expressão de novas idéias e possivelmente novos caminhos para a resolução de problemas.

Criatividade é " $[\ldots]$ dar existência, estabelecer relações até então não estabelecidas pelo universo dos indivíduos visando um determinado fim." (NOVAES, 1972, p. 17). Marcelo Galvão (1999) enfatiza que: "Mais do que ensinar criatividade deve-se pensar em desaprender os bloqueios e a redescoberta do potencial às vezes adormecido. ” (p. 36, grifo nosso).

Um trabalho com esta pretensão deve romper com a educação voltada para a mera aquisição de conhecimentos com enfoque apenas no cognitivo e trazer conteúdos e dinâmicas que envolvam as pessoas no seu processo de descoberta, ou seja, através da experimentação ativa da atividade criadora.

3 WECHSLER, Solange M. Criatividade: descobrindo e encorajando. Campinas: Psy, 1993. Apud GODOY, 1996, p. 89.

4 MCMURRAY, Janice. Creative Arts with Older People. London: Haworth, 1990. Apud GODOY, 1996, p. 36 
A experiência que leva ao despertar da criatividade pode ajudar o indivíduo idoso a desenvolver sua autonomia para escolher qual capacidade criadora deseja desenvolver e canalizá-la para setores de sua realização pessoal. Criatividade também precisa ser vivenciada e construída no exercício das pequenas coisas, no cotidiano.

\section{Oficinas Pedagógicas como Espaço para o Despertar da Criatividade e Educação Permanente na Velhice}

Apostando na possibilidade de uma velhice criativa, introduziu-se o instrumento e as estratégias didáticas da Oficina Pedagógica para ajudar idosos no despertar da criatividade e buscar corroborar questões de pesquisa que confirmassem a importância da abertura desses espaços.

De acordo com Vieira e Volquind, (2002, p. 11): “Oficina é uma modalidade de ação.” Toda oficina necessita promover a investigação, a ação, a reflexão; combinar o trabalho individual e a tarefa socializada; garantir a unidade entre a teoria e a prática. O pensar, o sentir e o agir são elementos permanentes numa Oficina de Ensino.

Neste sentido, viabilizou-se um lugar onde a teoria, o tempo, as pessoas e os objetos produziram momentos que possibilitou ao idoso assumir a autoria do seu próprio roteiro criativo.

O discurso intelectual foi necessário, e a teoria enfocou como temas principais: apresentando e desmistificando a criatividade; processo criativo e bloqueios à criatividade. Como temas transversais da oficina, enfocou-se educação permanente e o envelhecimento bem sucedido.

A alegria e a diversão fizeram parte do processo, assim como, a ação e reflexão também estiveram presentes nas dinâmicas, nos momentos de reflexão e vivências.

Ander-Egg, ${ }^{5}$ apud Vieira; Volquind (grifo nosso), sobremaneira também iluminou a prática realizada através do suporte dos " [ . . ] oito (08) princípios pedagógicos para uma oficina de ensino" que, resumidamente, podem ser descritos como:

a) aprender fazendo: aprender vendo é mais formador do que aprender por comunicação verbal de idéias;

\footnotetext{
5 ANDER-EGG, Ezequiel. El taller una alternativa para la renovacion pedagógica. Buenos Aires: Magistério, 1991. Apud VIEIRA; VOLQUIND, 2002, p. 20-21.
} 
b) metodologia participativa: participar se aprende participando e não teoricamente;

c) pedagogia da pergunta: buscar respostas sem certezas absolutas; desenvolver a capacidade de reflexão é ter condições de apropriarse do saber;

d) trabalho interdisciplinar: atuar no âmbito onde muitas áreas do conhecimento se articulam sob diferentes perspectivas;

e) visa uma tarefa comum: envolve todos os componentes do grupo de forma autogestionária;

f) caráter globalizante e integrador: deve superar a dissociação entre corpo e mente-espírito; buscar o desenvolvimento do ser humano que é ao mesmo tempo ação, cognição e afeto;

g) implica e exige trabalho grupal: procurar promover a busca de resposta aos problemas, ricas de conteúdo e vivências;

h) integração da docência, da investigação e da prática em um só processo: realizar um projeto de trabalho, com reflexão teórica, com teoria iluminando e orientando a prática.

Cada participante assume o papel de quem aprende para mudar. Esta modalidade de ação não se aplica a qualquer conteúdo ou curso. Necessário um mínimo de orientação teórica e serem sujeitos ativos de sua própria formação.

É importante trazer, ainda, o conceito de Educação Permanente, ou de educação ao longo de toda a vida que representa segundo Delors ${ }^{6}$, apud Palma; Cachioni, uma construção contínua dos conhecimentos e aptidões humanas, da sua capacidade de discernir e agir. As missões que cabem à educação, e as múltiplas formas de que se podem revestir, fazem com que englobe todos os processos que levam as pessoas, desde a infância até ao fim da vida, a um conhecimento dinâmico do mundo, dos outros e de si mesmas.

Para dar conta dessa missão que se impõe, a educação deve ser capaz de organizar-se em torno de quatro grandes eixos. Estes eixos são os "[ ... ] quatro pilares da educação permanente da UNESCO" (COSTA, 2000, p. 49, grifo nosso), conforme segue:

${ }^{6}$ DELORS, Jacques et al. Educação: um tesouro a descobrir. In: . (Org.). Relatório para a Unesco da Comissão Internacional sobre Educação para o Século XXI. 3. ed. São Paulo: Cortez, 1999. Apud PALMA; CACHIONI, 2002, p. 1102. 
a) aprender a ser: preparar-se para agir com autonomia, solidariedade e responsabilidade; descobrir-se reconhecendo suas forças e seus limites; construir um projeto de vida que leve em conta o bem-estar pessoal e da comunidade;

b) aprender a conviver: ter a capacidade de comunicar-se, interagir; valorizar o saber social; compreender o outro e a interdependência entre todos os seres humanos; participar e cooperar; valorizar as diferenças, gerir conflitos e manter a paz;

c) aprender a fazer: aprender a praticar os conhecimentos adquiridos; adquirir competências que tornem a pessoa apta a enfrentar situações e a trabalhar em equipe;

d) aprender a aprender: despertar a curiosidade intelectual, o sentido crítico, a compreensão do real e a capacidade de discernir; construir as bases que permitirão ao indivíduo aprender ao longo de toda a vida.

Este referencial teórico norteou o papel de educadoras neste processo de pesquisa. A seguir apresenta-se as questões de pesquisa relacionadas à oficina pedagógica como espaço para o exercício da criatividade e educação permanente na velhice que dirigiram e foram sendo confirmadas durante $o$ desenrolar do processo pedagógico-investigativo em foco. Isto aparece em depoimentos orais e também nas respostas escritas às questões feitas ao longo da Oficina e no questionário de avaliação final desta.

A Questão de Pesquisa 1 (um) "O espaço educativo da Oficina Pedagógica de Criatividade ajuda o idoso a entrar em contato com seu potencial criativo", já aparece confirmada nas avaliações feitas no primeiro dia da Oficina quando por escrito os participantes disseram: "Dia cheio de criatividade"; "Sentiu-se artista"; "Colocou a imaginação a funcionar"; "Conduziu à reflexão"; "Percebeu suas potencialidade". Expressões com denotativos de aprendizado como: "Proveitoso, produtivo, aprendeu”; "Quer colocar em prática o que aprendeu”, também corroboram esta questão de pesquisa, uma vez que os temas trabalhados nesse dia enfatizaram o inesgotável potencial criativo inerente a todos e a possibilidade de desenvolvê-lo por meio de espaços e vivências criadoras.

Todos os participantes, na avaliação final, reforçaram a importância de espaços educativos para o exercício da criatividade na velhice e um deles relatou que: "Há poucas opções para extravasar a sensibilidade educativa. 
As soluções inteligentes estão na mão das pessoas que apostam na energia, no movimento e na visão dos idosos."

Uma população como a do NETI, engajada, inserida em um processo de educação permanente, conhece o papel da Ciência e da Universidade na construção de uma velhice bem sucedida e por isto sabem reivindicar ações e soluções "[ . . . ] das pessoas que apostam na energia, no movimento e visão dos idosos."

Por outro lado, outros idosos alijados da participação social, vivem enclausurados num mundo que de criativo e reivindicativo nada tem. Todo ser humano, no entanto, quer vida e criar também é vida. Esta afirmação pode levar a outras reflexões relacionadas ao papel educativo da Gerontologia na sociedade. Um especialista em gerontologia terá sempre uma dimensão educacional em seu trabalho a ser vivenciada. A este respeito Costa (2001, p. 68), diz ser o educador " [ . . . ] um dirigente, um organizador, um criador de acontecimentos." Para ele, é pelos acontecimentos que se mostrem capazes de produzir que o educador imprime o caráter e define a identidade, a especificidade do processo por ele orientado. A credibilidade de um educador não nasce de um discurso de palavras, mas sim, do curso dos acontecimentos que ele for capaz de engendrar.

Quanto à eficácia do modelo de Oficinas Pedagógicas que coloca o aprender fazendo como mais formador e vigorizante do que aprender simplesmente por comunicação verbal de idéias, somado aos referenciais teóricos sobre Criatividade que enfatizam a importância do exercício da criação, a experiência realizada reuniu muitos depoimentos positivos que confirmam que este modelo é bastante adequado na vivência da criatividade na velhice. Isto reforça que apenas, o conhecimento intelectual sobre o fenômeno da criatividade, embora importante, não basta para favorecer a expressão do potencial criador do idoso, isto é, existe a incompletude da teoria e conseqüentemente a necessidade de uma prática reflexiva para o favorecer a criatividade.

Apostou-se ainda, na importância de um clima positivo em um trabalho da natureza do aqui relatado e por isto formulou-se a questão: “Oferecer um clima psicológico que promova um ambiente encorajador e positivo em que o idoso se sinta seguro e livre para expor suas idéias sem medo da avaliação e da crítica, favorece a expressão do potencial criador desse idoso" (Questão 3). Esta questão de pesquisa pode ser validada nos diversos depoimentos dos quais ressalta-se expressões indicando sentimentos 
positivos como: "Liberdade"; "Se desprendeu de tudo"; "[ . . ] deixoume tranqüila"; e quanto ao clima ambiente: "Alegre, animado, descontraído, agradável"; "[...] leve”; "[ . . ] cheio de criatividade" e outros como "[...] auto-estima em alta"; "Boas vivências com outras pessoas/companheirismo"; "Integrado”; "[...] convívio e experiências agradáveis."

A experiência de estar vivenciando bons momentos, o sentimento de pertença, os sentimentos positivos emergidos de um trabalho como este, confirmam que para a vivência da criatividade, é preciso levar em conta o complexo das condições estimuladoras e dos fatores energizadores, tal como também afirma Novaes (1972).

A análise ainda, dos resultados do questionário de avaliação final, pôde-se constatar que dos treze alunos que o responderam, doze alegaram ter se sentidos encorajados a criar. Esse encorajamento se referia ao ambiente, ao grupo, aos tipos de dinâmicas e à maneira como foram conduzidas. Apenas uma aluna diz que isto não ocorreu, pois precisa silenciar para pensar. Essa mesma participante esclarece em outro momento, que é bastante tímida e fechada e que não gosta de se expressar em público.

Durante a Oficina Pedagógica pôde-se encontrar/desenvolver em vários momentos, diversas formas de expressão, fortalecendo questões que evidenciam a possibilidade da relação entre criatividade e terceira idade. Considerando isto, três pressupostos nortearam todo o tempo as atividades:

\section{"É possível despertar o potencial criativo dos idosos." \\ "Criar gera prazer e alegria." \\ "A experiência do processo criativo enriquece a vida das pessoas."}

Estas questões de pesquisa estão intrinsecamente relacionadas, pois o despertar, o prazer e o enriquecimento que a criatividade proporciona, não podem ser vivenciados de forma isolada. Isto ficou evidente nos relatos dos participantes e também nas expressões dos vários autores pesquisados.

Para Lowen (1984) a auto-expressão, a criatividade e o prazer encontram-se integrados. Toda forma de auto-expressão possui elementos criativos, acarretando prazer e satisfação. Percebendo-se isto em depoimentos como:

"Me sinto mais solta, tenho novos meios de comunicação." 
"Despertou uma parte do espírito que estava adormecido."

"[ . . . ] pessoa que tiver oportunidade... certamente entrará em contato com sua criatividade."

"Apesar da idade temos que continuar procurando novas idéias e usar muito nossa criatividade."

"Descobri que também sou capaz de criar."

"O despertar da criatividade faz o idoso se sentir útil."

"O idoso necessita demonstrar as suas potencialidades."

"O ser humano só precisa de incentivo para colocar em prática todo o seu potencial."

"O idoso é mais aberto a esse despertar."

"Dê oportunidade ao idoso e grata será a surpresa."

Para Moustakas, ${ }^{7}$ apud Godoy, permitir com que o idoso explore essas expressões é garantir a utilização de seu potencial criativo, é não só torná-lo mais seguro, mais afetivo socialmente, como habilitá-lo a desenvolver o seu "eu", atualizando suas capacidades de produzir e de interagir de forma criativa no mundo.

A criatividade resulta do desejo de prazer e da necessidade de autoexpressão. O prazer fornece a motivação para uma vida criativa proporcionando ao indivíduo uma maior independência e autoconfiança, estimulando-o a perceber suas potencialidades e limites. A integração do prazer e da alegria ao criar pôde ser observada durante as atividades desenvolvidas na oficina. No trecho da poesia a seguir, criada durante uma das vivências, um dos participantes (J. E. L, 60 anos), deixa isto bastante evidente:

\section{Alegria de ser, ter, ver, Alegria de amar, compartilhar, dar, transmitir, Alegria de abraçar o mundo, Alegria de viver sem temor ou medo, Alegria da vida.}

O despertar da criatividade é ainda ressaltado na conclusão de um dos alunos ao chegar para o segundo dia da Oficina: "Passei a olhar com todos os olhos. " Esta afirmação é muito significativa e nos revela um ser que

7 MOUSTAKAS, Clark. Creativity and Conformity. New York: D. Van Nostrand, 1967. Apud GODOY, 1996, p. 28. 
despertou, que atentou, que alertou para o seu potencial perceptivo, que ampliou sua visão de mundo.

O trecho da poesia a seguir, também criada por um dos participantes da Oficina Pedagógica de Criatividade para Idosos, reforça o que Wechsler, ${ }^{8}$ apud Godoy, diz sobre a velhice: é o momento de estimular/despertar a pessoa a realizar sua missão criativa. Para Kneller (1973) as formas criativas que exigem maior reflexão e experiência são melhor exploradas nos idosos.

"Foram momentos descontraídos e com toda esta minha idade, setenta anos vividos começo a despertar a criatividade." (V. T., 70 anos).

Educar, conforme Costa (2000), é criar espaços para que o educando possa empreender, ele próprio, a construção do seu ser, ou seja, a realização de suas potencialidades em termos pessoais e sociais. O educador deve desenvolver seu trabalho levando em conta os quatro pilares da educação permanente da UNESCO e estes estiveram presentes na construção e desenvolvimento da Oficina de Criatividade. Algumas questões de pesquisa relacionadas com a educação permanente puderam ser corroboradas, conforme segue:

a) questão de pesquisa 1 - envelhecer com a perspectiva de educação permanente pressupõe espírito aberto, interesse por projetos, por pessoas;

b) questão de pesquisa 2 - a sensibilização, estímulos, o encorajamento e a crença no potencial pessoal é condição importante para o crédito numa educação permanente ao longo da vida.

Estas duas questões de pesquisa foram comprovadas pelos depoimentos:

"[ . . ] aprender sempre [...]."

"[ . . ] senti enorme alegria ao perceber que sei escrever em forma de versos [ . . . ]."

"[ . . ] descobri um criar que não imaginava ter [ . . . ]."

"O ser humano só precisa de incentivo para colocar em prática todo o seu potencial."

"[ . . ] descobri que também sou capaz de criar."

"[ . . ] todos nós podemos criar e isto, com certeza, vai ajudar a ter um envelhecimento bem-sucedido."

8 WECHSLER, Solange M. Descobrindo e Encorajando. Campinas: Psy, 1993. Apud GODOY, 1996, p. 89. 
"[...] aqueles que se encontram adormecidos despertam para o criar, e os mais tímidos podem ser incentivados, sentir-se valorizados $[\ldots] . "$

"[...] espaços educativos de criatividade nos ajudam a valorizar toda nossa cultura adquirida [ . . . ]."

"[ . . ] participar em grupo [ . . ]."

"[ . . . ].o contato com pessoas possibilita desenvolver novas habilidades [...]."

Os autores pesquisados neste trabalho, também corroboraram estas hipóteses com as afirmações que se seguem: para Delors, ${ }^{9}$ apud Palma; Cachioni, o processo educativo deve estimular a pessoa a descobrir, despertar e incrementar suas possibilidades criativas, atualizando assim, o tesouro escondido que cada um tem. Neri e Cachioni, ${ }^{10}$ apud Palma; Cachioni, ressaltam que as oportunidades educacionais são apontadas como importantes antecedentes de ganhos evolutivos na velhice, pois esses espaços intensificam os contatos sociais, a troca de vivências e de conhecimentos e por promoverem o aperfeiçoamento pessoal.

Desta forma, deve-se investir na educação ao longo da vida, pois além do aumento crescente de idosos porque passa a realidade atual, precisase ocupar melhor o tempo livre dessa população. Educar para a criatividade pressupõe promover não só atividades criadoras, mas, sobretudo, atitudes que desenvolvam a originalidade, apreciação do novo e percepção da realidade.

Cabe destacar um veemente depoimento que reforça a importância da educação ao longo da vida:

Apesar da idade temos que continuar procurando novas idéias e usar muito nossa criatividade. Neste curso, aprendemos a desenvolvê-la ainda

9 DELORS, Jacques et al. Educação: um tesouro a descobrir. In: DELORS, J. (Org.). Relatório para a Unesco da Comissão Internacional sobre Educação para o século XXI. 3. ed. São Paulo: Cortez, 1999. Apud PALMA; CACHIONI, 2002, p. 1102.

${ }^{10}$ NERI, Anita Liberalesso.; CACHIONI, Meire. Velhice Bem-Sucedida e Educação. In: NERI, Anita Liberalesso; DEBERT, Guita. Grin. (Org.). Velhice e Sociedade Campinas: Papirus, 1999. p. 113-140. Apud PALMA; CACHIONI, 2002, p. 1102. 
mais, pois sabemos que a mente não gasta com a idade, o que estraga é a falta de uso da mesma. Aprendi que nada está acabado, sempre há o que fazer. (Y. M. P. C., 70 anos).

\section{Considerações Finais}

A Educação Permanente abrange várias áreas da vida do ser humano, e conseqüentemente, está atrelada à criatividade. Para criar é necessário uma busca constante de conhecimento e autoconhecimento que é um componente poderoso para o exercício da vivência criativa. Possibilita ainda, a melhoria da auto-estima, qualidade de vida, relações pessoais e a conquista de um bom nível de independência e de autodeterminação.

Viver criativamente educando-se ao longo da vida estimula a flexibilidade e abertura ao novo, componentes essenciais para um envelhecimento bemsucedido.

É importante ainda, refletir-se sobre a prática da gerontologia e a necessidade de que o discurso proferido aos idosos seja vivenciado no cotidiano do papel social que cabe ao gerontólogo como trabalhador e cidadão.

Uma prática educativa que deve ser vivida e ampliada à luz de teorias e que refletem a complexidade humana exigindo flexibilidade e despojamento perante o novo.

Sabe-se da inexistência de manuais e receitas prontas para uma atuação eficaz. É preciso muitas vezes improvisar, mudar, sair do caminho planejado e dos saberes estabelecidos; ter consciência da incompletude das verdades especializadas.

Aprendeu-se que tanto a Fisioterapia, quanto o Serviço Social e a Pedagogia, têm papel fundamental na construção de um envelhecimento saudável e que suas dimensões educativas são imprescindíveis na Gerontologia.

Descobriu-se que as atitudes positivas de um pesquisador do ponto de vista de uma atitude científica, é semelhante às características de uma pessoa que vivencia com plenitude sua criatividade. Precisa-se do lado racional, crítico e objetivo, mas deve-se estar exercendo outros como o da imaginação, reflexão, humildade e persistência. 
A acomodação não deve estar presente num trabalho que tenha como filosofia à interdisciplinaridade porque a coragem de ousare sair do convencional são exigências constantes de um trabalho dessa natureza.

É necessário que outros educadores ampliem exercícios pedagógicos, e que prática como estas sejam levadas a idosos de todas as classes sociais.

Importante que pesquisas científicas sejam substancialmente realizadas para que se tenha num futuro próximo, teorias que ajudem a entender melhor a relação entre velhice e criatividade.

Sugere-se, ainda, que o tema Criatividade seja inserido nos currículos dos cursos de Monitores de Ação Gerontologica e também nos cursos de Especialização em Gerontologia.

Tem-se a convicção de que a Gerontologia é um "prato cheio" para quem quer viver um caminho profissional repleto de descobertas, novidades e, portanto, passível de criatividade. Gerontologia, pois, é para quem gosta de ousar, de se aventurar, de ir em busca do novo, sem perder a perspectiva de construir cientificamente, de fazer avançar a epistemologia. Um gerontólogo com uma visão educativa do seu trabalho é alguém que está querendo ver com "todos os olhos." Gerontologia é para profissionais abertos à criatividade.

\title{
EDUCATIONAL WORKSHOPS IN PRACTICE OF CREATIVITY AND PERMANENT EDUCATION IN OLD AGE
}

\begin{abstract}
The objective of this article is to show the relation between the Pedagogic Workshops and the educative environment, to instigate the creativity and stimulate the permanent education of the elders. It is a result of a practical intervention made by a Social Assistant and a Physiotherapist with seventheen elder students from NETI (Nucleo de Estudos da Terceira Idade) of the Universidade Federal de Santa Catarina - UFSC, through a Pedagogic Workshops: entitled "Creativity Instigation". The pedagogical practice was used as a measurement of a scientific exercise of knowledge production based on a monograph, which gave the Gerontology Specialist title to the authors. The monograph "The Pedagogic Workshops space on the creativity exercise and permanent elder education" discourses over theoretic references about creativity, permanent education, Pedagogic Workshops and presents research
\end{abstract}


questions that were confirmed through investigations and quantitative approach. Such hypotheses reassure the value of the creativity in the elder's life. They bring pleasure and joy and improve their lives. These questions may lead to the creation of favorable and positive pedagogic places where the creativity potential of the elders may be encouraged. This will certainly bring a permanent education perspective on the elders' aging process. Finally this article presents Gerontology as a field full of creative possibilities demanding professionals opened to creativity.

Keywords: Creativity. Elders. Permanent Education. Pedagogic Workshops.

\section{REFERÊNCIAS}

COSTA, Antonio Carlos G. Aventura Pedagógica. 2. ed. Belo Horizonte: Modus Faciendi, 2001.

. Protagonismo Juvenil. Salvador: Fundação Odebrecht, 2000.

GALVÃO, Marcelo. Criativa-mente. 2. ed. Rio de Janeiro: Qualitymark, 1999.

GODOY, Maria de Fátima G. Criatividade e Integração Vital com Idosos. 1996. Dissertação (Mestrado em Psicologia Clínica) - Pontifícia Universidade Católica de Campinas, Campinas, 1996.

KNELLER, George Frederick. Arte e Ciência da Criatividade. 3. ed. São Paulo: Ibrasa, 1973.

LOWEN, Alexander. Prazer: uma abordagem criativa da vida. 5. ed. São Paulo: Summus, 1984.

MINAYO, Maria Cecília de Souza. O Desafio do Conhecimento: pesquisa qualitativa em saúde. São Paulo: Hucitec; Rio de Janeiro: Abrasco, 1996.

NERI, Anita Liberalesso. E por Falar em Boa Velhice. Campinas: Papirus, 2000. 
NOVAES, Maria Helena. Psicologia da Criatividade. Petrópolis: Vozes, 1972.

PALMA, Lúcia Saccomori; CACHIONI, Meire. Educação Permanente: perspectiva para o trabalho educacional com o adulto maduro e com o idoso. In: FREITAS, Elizabete Viana de.; PY, Ligia; NERI, Anita Liberalesso; CANÇADO, Flávio Aluízio Xavier; GORZONI, Milton Luiz; ROCHA, Sônia Maria da. (Org.). Tratado de Geriatria e Gerontologia. Rio de Janeiro: Guanabara Koogan, 2002. P. 1101-1109.

PFEIFER, Suzana Susi. Criatividade: um estudo nas fronteiras da ciência, da arte e da espiritualidade. 2001.256 f. Tese (Doutorado em Engenharia) Programa de Pós-Graduação em Engenharia de Produção, Universidade Federal de Santa Catarina, Florianópolis, 2001.

TRIVIÑOS, Augusto Nibaldo Silva. Introdução a Pesquisa em Ciências Sociais: a pesquisa qualitativa em Educação: o Positivismo, a fenomenologia, o Marxismo. São Paulo: Atlas, 1987.

VIEIRA, Elaine; VOLQUIND, Lea. Oficinas de Ensino: o quê, por quê? Como? 4. ed. Porto Alegre: Edipucrs, 2002. (Série educação, 3)

\section{ANEXO A - A Oficina Pedagógica: Despertar para o Criar}

Aqui apresentamos breve relato da Oficina Educativa que serviu como base para a pesquisa realizada, sendo que é possível visualizar conteúdos e dinâmicas realizadas:

\section{Primeiro dia:}

\section{Período matutino:}

- Facilitadoras apresentam e esclarecem os objetivos da Oficina Pedagógica Despertar para o Criar.

- Dinâmica de grupo de conteúdo lúdico para apresentação dos participantes; 
- Dinâmica de grupo para aquecimento do conteúdo teórico a ser apresentado a seguir;

- Apresentação teórico-expositiva, com auxilio de transparência sobre o tema: Apresentando e Desmistificando a Criatividade;

- Intervalo para o lanche;

- Dinâmica de grupo visando à sensibilização auditiva;

- Dinâmica de grupo para a criação de uma estória improvisada de forma coletiva;

- Dinâmica de grupo com técnicas de relaxamento e após conversas em duplas sobre o contato de cada participante com suas habilidade e sucessos.

\section{Período Vespertino:}

- Dinâmica de descontração com música;

- Confecção coletiva de um mural sobre Criatividade;

- Dinâmica de grupo: Construção de escultura grupal com a utilização de seus corpos onde deveria representar o tema: Envelhecimento Bem Sucedido;

- Apresentação teórico-expositiva com auxílio de transparência sobre o tema: Processo Criativo;

- Intervalo para o lanche;

- Alongamento corporal coletivo, com orientação de facilitadora;

- Avaliação, por escrito do primeiro dia da Oficina “Despertar para o Criar".

\section{Segundo dia:}

\section{Período Matutino:}

- Dinâmica de Grupo: jornal falado;

- Apresentação teórico-expositiva com auxilio de transparência sobre o tema: Bloqueios à Criatividade;

- Intervalo para o lanche;

- Elaboração individual de poesia com utilização de técnica de relaxamento induzido pela facilitadora, escrita e leitura individual das poesias criadas. 


\section{Período Vespertino:}

- Dinâmica de aquecimento e formação de dois (02) grupos;

- Dinâmica para integração de todos os conhecimentos sobre criatividade: Criação e Apresentação de uma Propaganda; Participantes utilizaram a linguagem teatral;

- Intervalo para o lanche;

- Preenchimento de questionário investigativo sobre as hipóteses levantadas pra a pesquisa;

- Dinâmica de encerramento. 